\title{
THE MOUNTAIN GORILLA AND ITS HABITAT IN THE BIRUNGA VOLCANOES
}

$\mathrm{T}$ HE mountain gorilla was first described scien. tifically by Matschie in 1903, from a specimen collected two years previously on the southern slopes of Mount Sabinio by a German, Captain von Beringe. It was named Gorilla gorilla beringei after its discoverer, to distinguish it from Gorilla gorilla gorilla, the West African forest race. An account of the mountain gorilla has been given by John Blower (Oryx, 3, No. 6 ; November 1956).

There is no marked difference in size between the mountain and forest gorillas; where there are differences these are due mainly to environmental influences. The chief distinguishing characteristic of the mountain race is the well-developed crest or 'helmet' of hair on the top of the head ; it occurs in both sexes, but is more pronounced in the male. An adult male gorilla is about $6 \mathrm{ft}$. in height when fully erect and weighs some $400 \mathrm{lb}$. In its natural habitat it is usually seen in a crouched or semi-erect position and impresses more by the immense bulk of the animal's body and by the girth of the chest and neck than by its height. The chest measurement of an adult male is in the region of $70 \mathrm{in.}$ The head, body and limbs are covered with coarse black hair except for the central part of the face from the eyes to the mouth, which is naked ; so, too, are the ears, the inside of the hands and the soles of the feet. The females are considerably smaller and probably do not exceed $4 \mathrm{ft}$. $6 \mathrm{in}$. in height.

The largest concentration of mountain gorillas is to the north-east of Lake Kivu in the Birunga volcanoes, which lie mainly in Belgian territory, but extend into Uganda. It is improbable that there can be more than a total of 1,000-1,500 mountain gorillas in existence to-day. This gorilla is found only at high altitudes in very mountainous country-6,000 ft. and above in Kayonza, 8,000 ft. and above in Birunga.

Traces of gorillas are found at all elevations from about $9,000 \mathrm{ft}$. to the summits of the mountains, but they appear to favour the Hypericum woodland zone or 'rugeshi'. They make forays into the bamboo zone in search of bamboo shoots, and to a lesser extent into the sub-alpine and alpine zones, but their beds are rarely found elsewhere than in the Hypericum woodland and this must be regarded as the true gorilla habitat. Gorillas are usually found in troops of 5-15, though several troops will sometimes join together to form a much larger group. Every troop seems to be made up of several family groups, each of an adult male with one or two females and in. mature animals, one of the males being dominant and recognized as leader of the troop. The low proportion of young animals is most noticeable and seems to indicate a very low breeding-rate. A high infant-mortality due to the depredations of leopards and to chest complaints may be a contributory factor.

Each troop has its own quite limited territory, in which it remains for weeks or months at a time and from which it is reluctant to move even when disturbed by human activity. Troops change their territory at different times of the year, and there are undoubtedly considerable seasonal movements in both the Birunga and Kayonza habitats. These movements are mainly influenced by food requirements.

Gorillas are entirely diurmal and spend most of the day feeding, when the troop keeps fairly close together and movement is slow. They make little noise apart from an occasional low staccato bark. Gorillas are entirely vegetarian, their food generally consisting of some part of the stem of a plant rather than the leaves.

Compared with most other animals, gorillas are easy to approach, and their senses of hearing and scent are not particularly keen. Like other primates, they seem to rely mainly on sight to warn them of danger. The alarm cry is loud and high-pitched, a mixture between bark and roar. This is a signal for the immediate retreat of the females and young, while the adult males remain as a rearguard.

Aggressiveness is very rare. There are very few records of deliberate attacks on human beings by gorillas, though there have been a number of reports of demonstrations by old males. Gorillas will, however, attack if wounded or cornered or if their young are threatened; then they are most formidable opponents. On the whole, however, the ferocity of gorillas has been greatly exaggerated, and, unless molested or provoked, they are normally most docile and harmless creatures.

They climb trees where necessary to obtain food or in order to construct beds, but their normal habit is terrestrial rather than arboreal. Beds are made by pulling down surrounding woody vegetation and forming it into a roughly circular or oval pad about 12 in. thick, 2-3 ft. in diameter, and slightly hollowed in the centre. Besides beds, gorillas sometimes make temporary resting places in the bamboo forest by bending over the feathery tops of a number of bamboos, thereby forming a springy and comfortable platform 6-8 ft. above ground-level, apparently for use during the day. All the beds are heavily fouled with excrement. Gorillas appear to construct fresh beds at frequent intervals and probably every day.

Little is known concerning the reproduction of gorillas; but the composition of the typical troop suggests a form of limited polygamy. The period of gestation is not known, but is probably not less than ten months.

There are few data on the rate of growth and development; but Pitman has recorded that a young mountain gorilla in captivity weighed $9 \mathrm{lb}$. two months after birth, and he suggests that puberty is reached at about 12-14 years of age. Nothing is known concerning the longevity of gorillas; but it would seem doubtful if they can have an expectation of life of more than about forty years.

The mountain gorilla is a very rare animal the continued survival of which is by no means assured unless more effective steps are taken for its preservation than is being done at present. The danger to the gorilla is indirect, through destruction of its habitat. This is particularly true in Uganda, where cultivation on the lower slopes of the Birunga volcanoes has already reduced the original gorilla habitat by half. Mining activities and new roads are likely soon to become a threat to the gorilla in the Kayonza for 